\title{
An Approach to Disinfection using Unmanned Aerial Vehicle/Quadcopter
}

\author{
Sanad S \\ UG Student, Karuna Medical College, Palakkad, India
}

\begin{abstract}
Necessity is the mother of invention. The objective of this research paper is to develop a drone which is able to disinfect places and surfaces which can be controlled by a person, who is in distant safer place. According to recent scientific studies, there are evidences that the pathogens are able to reside in different surfaces from few hours to several days. This drone will be able to kill or inactivate viruses and bacteria which cause different infections. The advantage of using drones in this method of disinfection is such that it avoids the risk facing by the person handling the chemical disinfectants, saving time, easy to access difficult sites low costs and less labor. We are designing a quad copter which is a multi rotor, in order to achieve the same.
\end{abstract}

Keyword: Disinfection, Unmanned Aerial Vehicle, Quad copter, Drone, Virus.

\section{I.INTRODUCTION}

Unmanned Aerial Vehicles (UAV) is aircraft without a human pilot and it is a type of unmanned vehicle. Flight of the UAV can be controlled either directly by a human operator or autonomously by an on board computer. Initially, these drones were mainly used in military application, now its use is rapidly expanding to commercial, scientific, recreational, agricultural and other applications such as aerial photography surveillance etc. Here we are designing a drone which is able to spray disinfectant and also able to emit uv-c rays.

Here we are using sodium hypochlorite as disinfectant to get rid of pathogens. Quad copter is a multi rotor helicopter; advantage of multi rotors over helicopters is such that it will be having more stability compared to former. Quadcopter is lifted and propelled by 4 motors. Frame of quadcopter can be arranged in the form of " $\times$ " or " + ". Here in this paper, we are designing the drone in the configuration of " $x$ ". With rotatory motion of the propellers, the quadcopter will be able to lift and able to fly.

Spraying unit includes tank pump and nozzles which are assembled to the basic configuration of drone. UV-C light is assembled to this drone for disinfection using rays. UV-C light is assembled to this drone for disinfection.

\section{AIM}

Obtaining thrust for flight to carry total load, to built a suitable quadcopter with stable flight control, designing mechanism for spraying disinfectant, mechanism to emit uv-c light rays from uv light, assembling the uv-c light in the drone.

\section{III.CONSTRUCTION}

The configuration of the drone is such that it will be having four ends in the form of " $X$ ".4 landing gears will be attached to the frame .Four brushless motors and its propellers are attached to four each legs. Output of each Electronic Speed Controller will be attached to each motor and its one input is connected to fight control board and other to Li-Po battery. There will be receiver attached to it, which is connected to fight control board. Receiver will receive the signal from the transmitter. Transmitter will be controlled by the operating person in whom the person can initiate, change the speed, direction, amount of liquid spraying through the nozzles, time of exposure of light to surfaces .The flight control board will be connected to the battery and they will be placed in the centre of the drone. This is the basic construction of the drone.

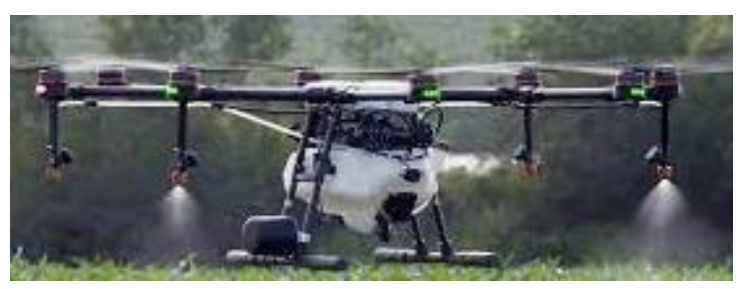

Figure 1: Drone spraying disinfectant

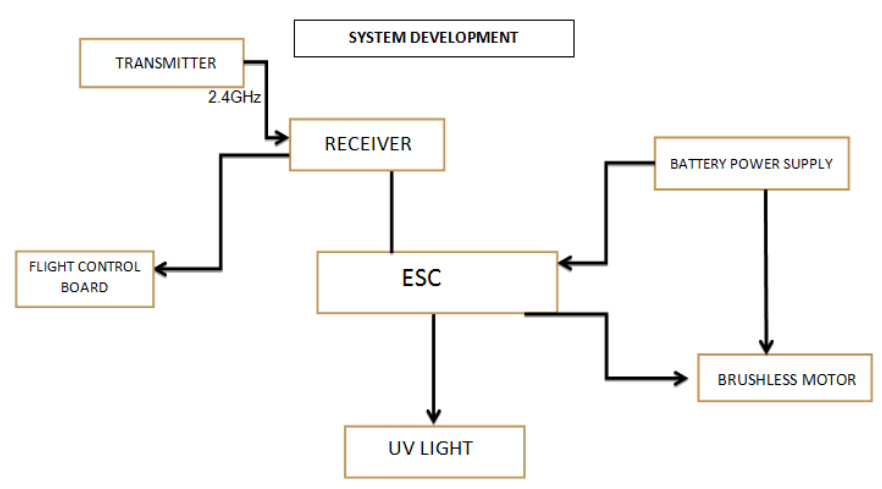

Figure 2: System development 
ISSN (online): 2581-3048

Volume 4, Issue 8, pp 1-5, August-2020 https://doi.org/10.47001/IRJIET/2020.408001

\subsection{Battery}

11.1V-5200Mah Li-Po battery is used in this quadcopter, which is rechargeable. Rated voltage is $11.1 \mathrm{~V}$ relatively low self discharge.

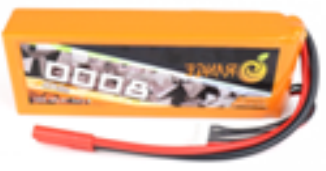

Figure 3: Battery

\subsection{Electronic Speed Controller}

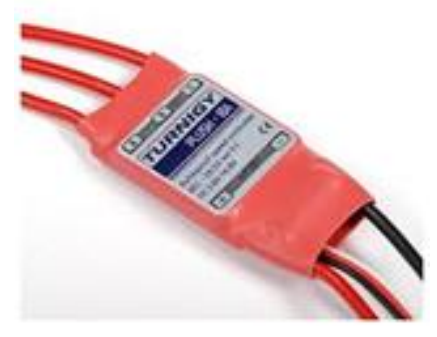

Figure 4: Electronic speed controller

It is an electronic circuit that controls and regulates the speed of an electronic motor. Brushless ESC systems basically create 3 phase AC power like a VFD, variable frequency drive, to run brushless motors. For a quadcopter 4 ESC s are required, one associated with each motor. Each ESC has present rating, which indicates the maximum current; it can deliver to a motor.

\subsection{Flight Control Board}

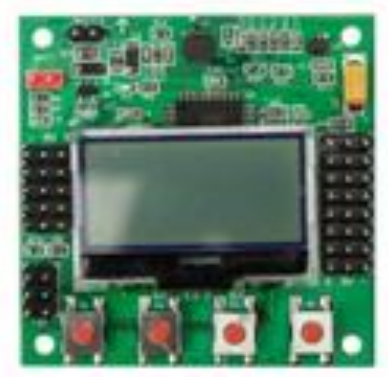

Figure 5: Flight control board

KK 2.1.5 multi motor LCD flight control Board is used in this project. Standard 6 pin AVR interface, Processor - Atmel 644 PA. It is a full autopilot capable for autonomous stabilization. Newly designed vibration isolation enables more accurate reading, allowing vehicles to achieve better overall flight performance. The two external SPI buses and six associated chip select lines allow for additional sensors and an SPI Interface payload.

\subsection{Transmitter}

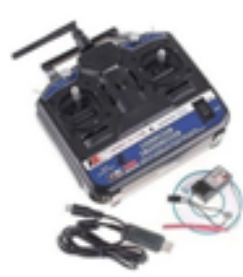

Figure 6: Transmitter

Avionic RCB OS-10 Transmitter, Drone sender is associate degree device that uses radio signals to transmit commands wirelessly via a group frequency over to the tuner that is connected. It transmits the signals to the receiver helps in controlling the quadcopter.

\subsection{Frame}

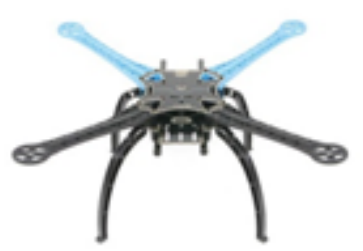

Figure 7: Frame

F330 glass fiber quadcopter frame is used, which is strong. It is having light weight, it decreases the total weight. It is having light weight. It de-creases the total weight Frame has wheel base of $330 \mathrm{~mm}$ and weights around $170 \mathrm{gm}$.

\subsection{BLDC motor}

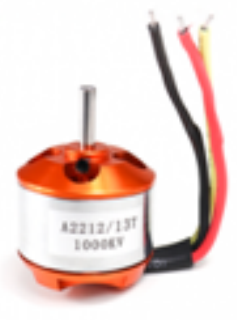

Figure 8: BLDC Motor

Also known as electronically commutated motor or Synchronous DC motor. Have high power to weight ratio, high speed electronic control. Motor spin the propellers to provide the drone with lifting and thrust. Two types of rating will be present on the motor, $\mathrm{Kv}$ rating and current rating. $\mathrm{Kv}$ rating indicates the RPM for $1 \mathrm{~V}$ of applied voltage .Current rating indicates the maximum current that the motor may safely draw. Brushless DC motor has low torque and high speed. A2212-1400KV motor is used in this paper. 
ISSN (online): 2581-3048

Volume 4, Issue 8, pp 1-5, August-2020

https://doi.org/10.47001/IRJIET/2020.408001

\subsection{Propeller}

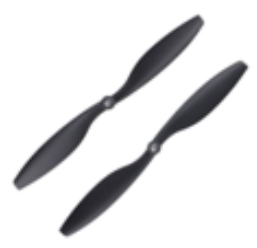

Figure 9: Propeller

It is a type of fan, which rotates in order to create thrust. Its motion will be according to its diameter and pitch. One pair will be clockwise rotating and another will be anticlockwise rotating.

\subsection{Receiver}

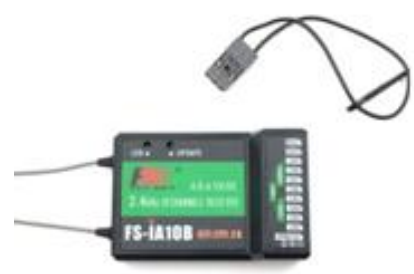

Figure 10: Receiver

Avionic OS-10 Receiver is used. It receives the signals from the transmitter. No of channels: 10. RF range: 2.405 $2.475 \mathrm{GHz}$.

\subsection{Brushed ESC}

Brushed ESC is used to for controlling $12 \mathrm{~V}$ water pump. At the output of ESC, water pump is connected.

\subsection{V DC submersible water pump}

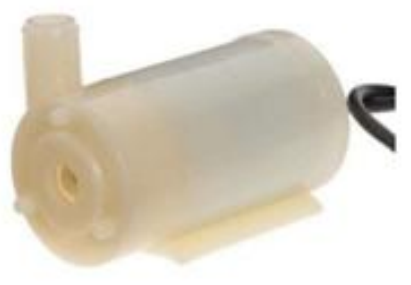

Figure 11: Water pump

It is used for pumping disinfectant. It is attached to disinfectant tank. It pumps out disinfectant into the nozzles and thus sprays the disinfectant.

\subsection{UV light}

This emits UV-C radiation, which can kill or inactivate microorganisms by destroying nucleic acid and disrupting their DNA, thus they will be unable to perform vital cellular functions. According to recent research, UV light is very efficient in destroying the microorganism.

\subsection{Disinfectant Storage}

It is a plastic tank which is capable of storage of $1 \mathrm{~L}$ of disinfectant. It is tilted to the side of the pump, in order to spray whole disinfectant.

\subsection{FPV Camera and transmitter}

This is First Person View camera which is connected to the transmitter and it can transmit the video signals to the receiver at the ground.

\section{MECHANICS OF FLIGHT CONTROL}

Motors on one diagonal rotate in the clockwise direction and on the other in the anti clockwise direction. Quadcopter movement is controlled by varying the relative thrust of each of the 4 rotors.

\section{Moving forward}

To move forward the power of the front motor to be reduced. This tilts the quadcopter forward and rotors provide sufficient thrust to move forward.

\section{Moving backward}

To move backward the power of back rotor will be reduced, tilting the quadcopter backwards.

\section{Other degree of freedom of movement}

1. Yaw: It is the movement of turning left and right. It is controlled by turning up the speed of a regular rotating motors and taking away power from the counter rotating.

2. Roll: It is the tilting towards left and side. Done by increasing the speed on one motor, and lowering on the opposite side.

3. Pitch: It is the movement towards up and down. It uses 2 nd set of motors.

$$
\begin{aligned}
& \text { FLIGHT DYNAMICS } \\
& \boldsymbol{U}_{1} \rightarrow \text { affects altitude } \\
& U_{2} \rightarrow \text { affects rotation in roll angles } \\
& U_{3} \rightarrow \text { affects pitch angle } \\
& U_{4} \rightarrow \text { affects yaw angle }
\end{aligned}
$$

$$
\begin{aligned}
& \text { Six Ouputs } \\
& \boldsymbol{X}, \boldsymbol{Y}, \boldsymbol{Z}, \boldsymbol{\theta}(\text { roll }), \Psi(\text { pitch }), \phi(\text { yaw })
\end{aligned}
$$


ISSN (online): 2581-3048

Propeller speed

1.Throttle:

$\boldsymbol{U}_{1}=\boldsymbol{b}\left(\Omega_{1}^{2}+\Omega_{2}^{2}+\Omega_{3}^{2}+\Omega_{4}^{2}\right)$

$U_{2}=b l\left(\Omega_{4}^{2}-\Omega_{2}^{2}\right)$

$U_{3}=b l\left(\Omega_{3}^{2}-\Omega_{1}^{2}\right)$

$U_{4}=d\left(\Omega_{2}^{2}+\Omega_{4}^{2}-\Omega_{1}^{2}-\Omega_{3}^{2}\right)$

On transformation using Inverted Matrix Method

$\Omega_{2}^{2}=\frac{1}{4 b} U_{1}-\frac{1}{2 b l} U_{3}-\frac{1}{4 d} U_{4}$

$\Omega_{2}^{2}=\frac{1}{4 b} U_{1}-\frac{1}{2 b l} U_{2}+\frac{1}{4 d} U_{4}$

$\Omega_{3}^{2}=\frac{1}{4 b} U_{1}+\frac{1}{2 b l} U_{2}-\frac{1}{4 d} U_{4}$

$\Omega_{4}^{2}=\frac{1}{4 b} U_{1}+\frac{1}{2 b l} U_{2}+\frac{1}{4 d} U_{4}$

\section{MECHANISM OF ACTION OF DISINFECTANTS AND UV RAYS}

Disinfectants are chemical agents which in activate or destroy microorganism on inert surfaces. They kill of the bacteria by causing the proteins to become damaged and outer layer of the bacteria cell to rupture. They kill the virus by, destroying the outer lipid layer. UV-C rays kill microorganisms by destroying the nucleic acid and disrupting their DNA, leaving them unable to perform vital cellular functions. These two units can be activate separately or both at the same time.

\section{DISINFECTANT MECHANISM OF SODIUM HY - POCHLORITE}

Sodium hypochlorite is a strong disinfectant, which is a pale greenish solution. It liberates chlorine, which helps in its disinfectant action. It has broad spectrum antimicrobial activity.

\section{SPRAYING METHOD USING SPRAYING NOZZLES}

Nozzles cause dispersion of liquid into droplets, which increases the surface area of distribution of liquid. We are using two fluid nozzles for its distribution.

\section{RESULT ANALYSIS}

The final result of this paper is a drone, which is able to disinfect places by spraying and using uv light.

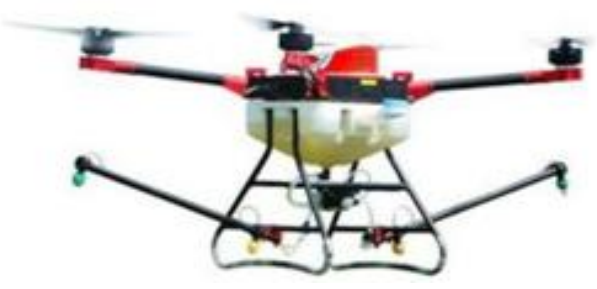

Figure 12: Disinfectant drone

\author{
https://doi.org/10.47001/IRJIET/2020.408001
}

We are assembling different components with at most care ad caution for attaining better results.

\section{CONCLUSION}

In this research paper, we are developing a drone, which is able to spray disinfectant, along with emitting uv-rays which helps in disinfection, which can be controlled by a person from a distant safer site. It reduces the risk of the laborers by avoiding direct contact with disinfectant and uv rays, less time and low labor cost.

\section{REFERENCES}

[1] Harsh Vardhan.P.D.P.R, Dheepak.S, Aditya.P.T, Sanjivi Arul, "Development of Automated Aerial Pesticide Sprayer" IJRET, Volume: 03 Issue: 04, 2014.

[2] Mark W. Mueller and RaffaelloD'Andrea. (2014), "Stability and Control of A Quadrocopter Despite the Complete Loss of One, Two, or Three Propeller", IEEE International Conference on Robotics \& Automation (ICRA), China.

[3] Ryan.T and Kim.H. J, (2013) "PD-tunable control design for a quadrotor," in AIAA Guidance, Navigation, and Control (GNC), Conference on. AIAA.

[4] Huang.Y,Hoffmann.W.C, Lan.Y, Wu.W,Fritz.B.K, (2009) "Development of a Spray System for an Unmanned Aerial Vehicle Platform", $A S A B E$, Vol. 25(6): 803-809.

[5] Misbah Rehman. Z, Kavya.B, Divya Mehta, "Quad copter for pesticide spraying" International journal of Scientific and Engineering Research, Volume 7, Issue 5, May-2016.

[6] Prof. Swati D Kale, Swati V Khandagale, Shweta S Gaikwad, Sayali S Narve, Purva V Gangal, "Agriculture Drone for Spraying Fertilizer and Pesticides" Volume 5, Issue 12, December 2015.

[7] VARIKUTI VASANTHA RAO et al., "MULTIPLE POWER SUPPLIED FERTILIZER SPRAYER", International Journal of Scientific and Research Publications, Volume 3, Issue 8, August 2013.

[8] S. MEIVEL M.E, DR. R. MAGUTEESWARAN Ph.D., N. GANDHIRAJ B.E, G. SREENIVASAN Ph.D., "Quadcopter UAV Based Fertilizer and Pesticides Spraying System", International Academic Research Journal of Engineering Sciences, ISSN No. 2414-6242, Volume 1,Issue 1, February 2016.

[9] C. ZHANG, J. M. KOVACS," The application of small unmanned aerial systems for precision agriculture: a review", Precision Agriculture, Springer. 
ISSN (online): 2581-3048

Volume 4, Issue 8, pp 1-5, August-2020 https://doi.org/10.47001/IRJIET/2020.408001

[10] $\mu \mathrm{AV}$ - Design and Implementation of an Open Source Micro Quadrotor" Christopher Lehnert and Peter Corke School of Electrical Engineering and Computer Science, Queensland University of Technology.

[11] D. Mellinger, M. Shomin, and V. Kumar, "Control of quadrotors for robust perching and landing, " in Proc. Int. Powered Lift Conf., Oct. 2010 Zhang.

[12] https://robu.in/product/a2212-10t-13t-1000kvbrushless-motor-without-soldered-connector/

[13] https://robu.in/product/orange-8000n-mah-4-cell-35c14-8v-lithium-polymer-battery-pack-lipo/

[14] https://oscarliang.com/what-is-esc-ubec-becquadcopter/

[15] https://robu.in/product/flysky-fs-ia10b-radio-receiver/

[16] https://robu.in/product/s500-multi-rotor-air-pcbframe-w-high-landing-gear-fpv-quad-copter/

[17] https://robu.in/product/ct6b-flysky-2-4ghz-6chtransmitter-wfs-r6b-receiver-mode-2/
[18] https://www.indiamart.com/proddetail/51-agriculturepestiside-spraying-drone-20143061148.html

[19] https://robu.in/product/kk2-1-5-multi-rotor-lcd-flightcontrol-board-with-6050mpu-and-atmel-644pa/

[20] https://robu.in/product/fs-th9x-2-4ghz-9ch-upgradetransmitter-with-fs-r9b-receiver-co/

\section{AUTHOR'S BIOGRAPHY}

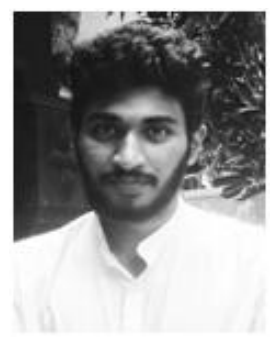

SANAD.S, UG student, Karuna Medical College, Palakkad, India

\section{Citation of this Article:}

Sanad S, “An Approach to Disinfection using Unmanned Aerial Vehicle/Quadcopter" Published in International Research Journal of Innovations in Engineering and Technology - IRJIET, Volume 4, Issue 8, pp 1-5, August 2020. https://doi.org/10.47001/IRJIET/2020.408001 